\title{
Penerapan Media Pembelajaran Game Berbasis Android Untuk Pengenalan Abjad (Studi Kasus: Tk Aisyiyah 2 Kec. Pinggir)
}

\author{
Irman Efendi ${ }^{1}$, Syerlie Annisa ${ }^{2}$ \\ 1,2) Teknik Komputer, AMIK Mitra Gama \\ Jl Kayangan No. 99 Mandau-Duri \\ Email: irmanefendi626@gmail.com
}

\begin{abstract}
ABSTRAK
Penggunaan smartphone, ipad, playbook, tablet pc dan sejenisnya lebih diminati saat ini daripada PC (Personal Computer). Penggunaan ponsel pintar tidak hanya bagi kalangan menengah atas, namun banyak anak usia dini yang telah difasilitasi perangkat tersebut oleh orang tua. Ponsel pintar bagi anak usia dini dimanfaatkan sebagai alat permainan untuk menghabiskan waktu luang mereka. Oleh karena itu game edukasi berbasis android dapat menjadi alternatif pengembangan aplikasi sebagai media belajar membaca, karena game edukasi dibuat tidak hanya untuk media pembelajaran tetapi juga untuk hiburan. Pembelajaran menggunakan game mampu memberikan kondisi lebih rileks yang dirasakan siswa ketika belajar, dengan kondisi ini siswa tidak akan mengalami kelelahan belajar karena materi yang disajikan dalam model game ini adalah betul-betul bentuk permainan. Pembuatan game edukasi berbasis android ini dirancang dengan bantuan aplikasi Adobe Flash CS6, Corel Draw, Adobe Photoshop dan Android Studio untuk menghasilkan permainan yang unik, menarik, dan edukatif yang dapat membantu meningkatkan minat anak dalam belajar abjad. Dengan dibuatnya game ini, diharapkan dapat membantu proses pembelajaran di TK Aisyiyah 2, Kec. Pinggir.
\end{abstract}

Kata kunci: Smartphone, Android, Game, Adobe flash CS6, Media pembelajaran

\begin{abstract}
The use of smartphones, ipad, playbooks, tablet PCs and the like is more popular today than PCs (Personal Computers). The use of smart phones is not only for the upper middle class, but many early childhood children have been facilitated by the parents. Smart phones for early childhood are used as a game tool to spend their free time. Therefore, Android-based educational games can be an alternative application development as a medium to learn to read, because educational games are made not only for learning media but also for entertainment. Learning to use games is able to provide more relaxed conditions that students feel when learning, with this condition students will not experience exhaustion of learning because the material presented in this game model is really a form of game. The creation of this android-based
\end{abstract}

UNITEX Vol 11 No.2 Juli - Desember 2018 | p-ISSN 2089-3957 | e-ISSN 2580-2585 
educational game was designed with the help of Adobe Flash CS6, Corel Draw, Adobe Photoshop and Android Studio applications to produce unique, interesting, and educational games that can help increase children's interest in learning the alphabet. With the making of this game, it is expected to help the learning process in TK Aisyiyah 2, Kec. Pinggir

Keywords: Smartphone, Android, Game, Adobe Flash Cs6, Instructional media

\section{Pendahuluan}

Pendidikan di Taman Kanak-kanak sangat penting dalam kehidupan seorang anak, karena pendidikan saat ini sebagai modal dasar untuk perkembangan selanjutnya. Untuk itu pembelajaran di TK haruslah di sesuaikan dengan perkembangan anak dan memberikan rasa aman, nyaman, menyenangkan dan menarik bagi anak serta mendorong keberanian. Dalam PP RI No.19 Tahun 2005 tentang standar pendidikan Bab. IV Pasal 19 dinyatakan bahwa: proses pembelajaran pada satuan pendidikan diselenggarakan interaktif, menyenangkan, menantang, memotivasi, peserta didik untuk berpartisipasi aktif serta memberikan ruang yang cukup bagi prakarsa, kreatifitas dan kemandirian sesuai dengan bakat dan perkembangan fisik dan psikologi peserta didik.

Kegiatan belajar mengajar pada taman kanak-kanak menggunakan metode pembelajaran antara lain metode bercerita, metode bercakap-cakap, metode tanya jawab. Namun, guru belum memiliki kemampuan dalam mengembangkan ide-ide yang dapat mengembangkan aspek perkembangan anak dalam kegiatan pembelajaran. Terutama pada aspek mengenal huruf. Guru langsung menyebutkan huruf sambil menunjuk bentuk huruf kemudian meberkan penugasan dalam bentuk lembar kerja. Dalam metode pembelajaran ini ditemukan kesulitan dan kendala bagi siswa untuk memahami materi yang diberikan oleh guru sehingga kemampuan anak mengenal huruf masih rendah, sulit dalam membedakan antar huruf dan cara pelafalannya yang belum tepat.

Guru belum menggunakan peralatan yang bervcariasi sehingga anak cepat merasa bosan dan lebih memilih untuk bermain di dalam kelas.Bahkan setelah berada di rumah, anak- anak tidak lagi mengulang kembali pelajaran membaca karena telah disibukkan dengan bermain bersama teman-teman di lingkungan rumah maupun bermain dengan ponsel pintar yang diberikan oleh orang tua mereka. Bahkan bersama teman-temannya tidak lagi melakukan permainan tradisional, namun memanfaatkan game yang ada di ponsel pintar untuk dimainkan bersama.Tingginya tingkat ketertarikan anak usia dini terhadap permainan yang terdapat di dalam ponsel pintar membuat anak sulit untuk diminta mengulang

UNITEX Vol 11 No.2 Juli - Desember 2018 | p-ISSN 2089-3957 | e-ISSN 2580-2585 
pelajaran membaca. Hal ini mengakibatkan terlambatnya anak-anak untuk dapat mengenal huruf dan kata. Game edukasi android dapat menjadi alternatif pengembangan aplikasi sebagai media belajar membaca, karena game edukasi dibuat tidak hanya untuk media pembelajaran tetapi juga untuk hiburan (E-learning Faculty Modules, 2012).

\section{Metode Penelitian}

Penelitian ini termasuk jenis penelitian research and development yaitu penelitian yang bertujuan mengembangkan sebuah game berbasis android sebagai media pembelajaran yang menarik dan interaktif bagi siswa Taman Kanak-Kanak Aisyiyah 2 Bustanul Athfal, Kec. Pinggir.

1. Tahapan Penelitian

Dalam penelitian ini penulis menggunakan model ADDIE (Analysis, Design, Devolopment Of Production, Implementation Or Delivery And Evaluation) yang dikembangkan oleh Reiser dan Mollenda. Menurut Sugiono (2009) Dalam melaksanakan penelitian penulis mengikuti beberapa proses yang dapat dilihat pada Gambar 1.

\begin{tabular}{|l} 
Analysis \\
Implementation
\end{tabular}$\Rightarrow \begin{aligned} & \text { Concept: menentukan tujuan aplikasi, bentuk aplikasi } \\
& \text { dan identifikasi program }\end{aligned}$

UNITEX Vol 11 No.2 Juli - Desember 2018 | p-ISSN 2089-3957 | e-ISSN 2580-2585 


\section{Hasil dan Pembahasan}

1. Tahap Analisis (Analysis)

Tahap analisis atau tahap pengonsepan adalah tahap untuk menentukan tujuan yang meliputi identifikasi audiency, jenis aplikasi presentasi, interaktif dan lain-lain. Tujuan dan penggunaan akhir program berpengaruh pada nuansa multimedia sebagai pencerminan dari identitas organisasi yang mengiginkan informasi sampai pada pengguna akhir.

Media ini dirancang untuk guru dan siswa. Bagi guru media ini bisa membantu guru dalam proses pembelajarannya. Agar proses pembelajaran bisa berjalan dengan lancar dan pastinya akan lebih menarik dengan bantuan media pembelajaran yang memanfaatkan teknologi yang ada seperti adobe flash. Sedangkan bagi siswa dapat menambah siswa dan membantu siswa untuk belajar mandiri di rumah. Dengan adanya media ini dapat membantu dan mempermudah guru dalm menyampaikan materi pelajaran adan siswa bisa membaca dan belajar materi-materi pelajaran dan disertai dengan contoh soal dan beberapa kuis untuk mengevakuasi kemampuan siswa yang telah di buat dalam bentu game.

Penyajian antar muka media ini menggunakan backgroud, animation serta musik sehingga menarik dilihat dan siswa tidak merasa bosan. Dilengkapi dengan contoh soal serta kuis yang disajikan dalam bentuk game untuk menarik minat siswa dalam belajar dan juga dilengkapi dengan materi-materi pekajaran yang di baca oleh siswa untuk mengulang pelajaran dirumah, Pembuatan desain media ini menggunakan Sofware Adobe Flash Cs6, Action Script2

2. Tahap Perancangan (Design)

A. Desain struktur navigasi

Struktur menu pada media pembelajaran dalam bentuk game ini menggunakan desain model, karena menu yang ada salaing berhubungan sehingga memungkinkan user untuk berinteraksi dan lebih banyak navigasi dengan menggunakan mouse dalam navigasi dalam mengeplorasi objek pada layar.

1) Struktur Navigasi Utama

Struktur navigasi utama menjelaskan lokasi halaman-halaman yang terdapat daam sistem dan adanya keterkaitan antar menu tersebut. Hal tersebut dapat dilihat pada gambar dibawah.

UNITEX Vol 11 No.2 Juli - Desember 2018 | p-ISSN 2089-3957 | e-ISSN 2580-2585 


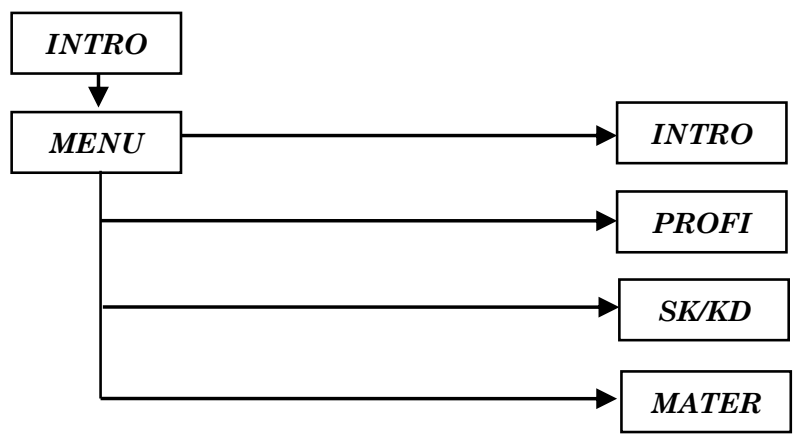

Gambar. 2 Struktur navigasi utama

2) Struktur Navigasi Profil

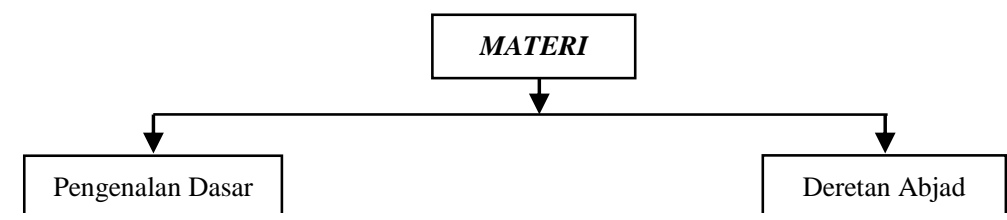

Gambar. 3 Struktur navigasi profil

3) Struktur Navigasi Materi

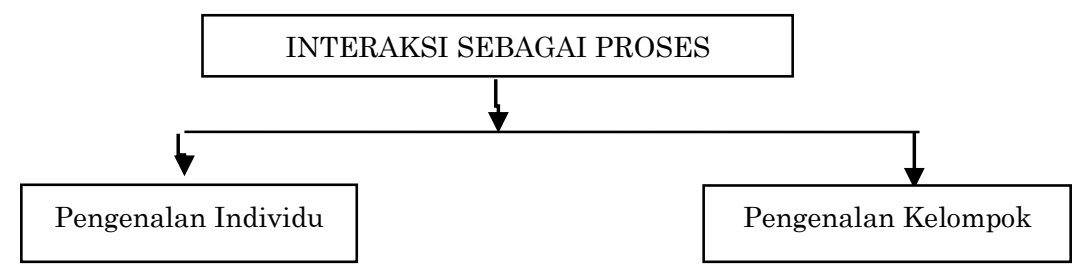

Gambar. 4 Struktur navigasi materi

4) Struktur Navigasi Soal Game

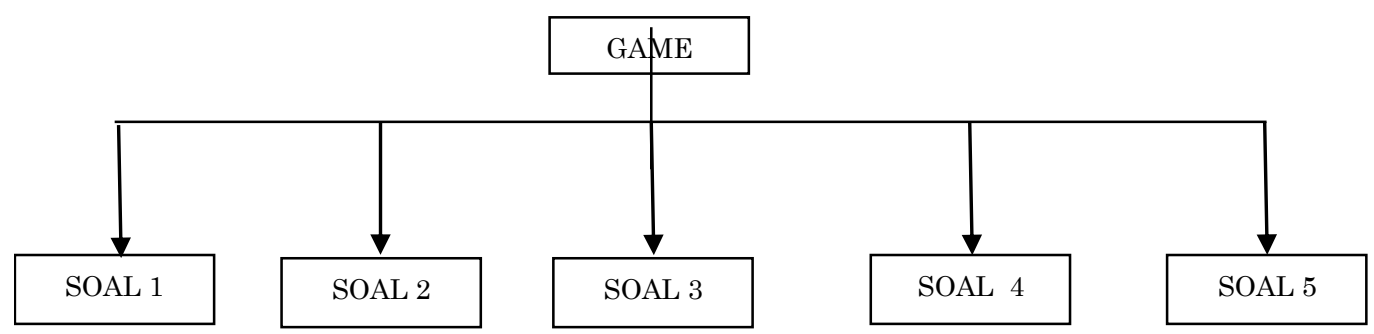

Gambar. 5 Struktur navigasi soal

UNITEX Vol 11 No.2 Juli - Desember 2018 | p-ISSN 2089-3957 | e-ISSN 2580-2585 


\section{B. Desain Storyboad}

Gambaran dari scene, bentuk visual desain, audio, durasi, keterangna dan narasi untuk suara akan dibuat pada desain storyboard. Hasil dari storyboard akan menjadi acuan dalam embuatan tampilan storyboard pada awal scene awal adalah halaman intro atau halaman pembuka, selanjutnya adalah scene untuk menu utama atau scene dari seluruh topik yang akan disampaikan pada keseluruhan movie. Desain storyboard secara dapat dilihat pada Tabel 1.

Tabel 1. Storyboard

\begin{tabular}{|c|c|}
\hline Scene 1 & Intro \\
\hline Scene 1 & Menu utama \\
\hline Scene 1 & Profil \\
\hline Scene 1 & materi \\
\hline Scene 1 & Game \\
\hline
\end{tabular}

\section{Desain Interface}

Aplikasi media pembelajaran ini didesain untuk siswa TK, maka desain yang dibuat banyak menggunakn unsur animasi agar siswa menarik menggunakan aplikasi ini seabagai media pembelajaran.dari semua itu disempurnakan dengan menambahkan musik sebagai latar sesuai dengan tema mata pelajaran.background dibuat pada setiap halaman agar lebih menarik siswa dalam melihat aplikasi ini. Hal ini dimaksudkan agar siswa tidak membosankan.

3. Tahap Pengembangan (Development)

Pada tahap ini dilakukan desain struktur navigasi, storyboard dan user interface

A. Desain Struktur Navigasi

Struktur menu pada media pembelajaran dalam bentuk game ini menggunakan desain model, karena menu yang ada salaing berhubungan sehingga memungkinkan user untuk beribteraksi dan lebih banyak navigasi dengan menggunakan mouse dalam navigasi dalam mengeplorasi objek pada layar.

B. Assembly (Pembuatan)

Assembly adalah tahap pembuatan seluruh objek multimedia berdasarkan desain yang telah dilakukan sebelumnya.

1) Pembuatan Objek Dan Background

Objek pada aplikasi ini digambar secara manual dengan menggunakan fasilitas Adobe Flash Cs6. Namun ada juga yang

UNITEX Vol 11 No.2 Juli - Desember 2018 | p-ISSN 2089-3957 | e-ISSN 2580-2585 
menggunakan fasilitas Corel Draw X4 dan Photoshop Cs3 serta ada menggambil walpaper yang sudah jadi. Untuk menggambar garis maupun bisang menggunakan tools line, oval, dan rectangle, sedangkan untuk pewarnaan menggunakan fasilitas paint. Sedangkan untuk efek animasi objek banyak menggunakan teknik animasi manggunakan frame, gradient, alfa, blur dan montion tween. Untuk backgound manggunakan gambar PNG yang telah didesain langsung dengan Corel Draw X4 secara keseluruhan, setelah objek maupun background digambar maka langkah selanjutnya adalah menconvert menjadi simbol dengan tipe grapic, hal ini dimasudkan agar gambar objek maupun background tersimpan pada panel galery, sehingga apabila kita ingin meletakkan gambar tersebut pada area kerja, kita tinggal menggambil denga cara mendrag gambar dari library ke area kerja tersebut.

2) Pembuatan Tombol Navigasi

Tombol pada apliasi dibuat dengan cara mengconvert teks atau gambar yang convert menjadi simbol dengan tipe button dan dikontrol dngan menggumakan actionsript. Lebih jelasnya dapat dilihat pada Gambar 6.

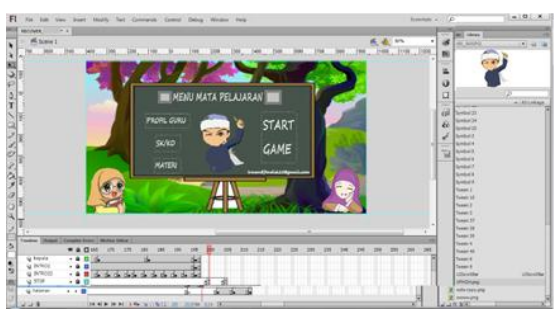

Gambar. 6 Tombol navigasi

3) Pemograman dengan Actionsript

Actionscript digunakan untuk menjalankan aksi pada frame maupun pada suatu tombol. Berikut bebrapa actionscript yang digukan dalam aplikasi ini:

a. Actionscript yang digunakan untuk menjalankan meu utama.swf

Next.onpress $=$ function ()\{

Ladmovienum(“menu.swf", 0 ), $\}$;

b. Script yang digunakan masing-masing tombol yang terdapat pada menu utama

UNITEX Vol 11 No.2 Juli - Desember 2018 | p-ISSN 2089-3957 | e-ISSN 2580-2585 
Untuk materi:

Next.onpress=function() \{

Loadmovienum("materi.swf", 0 ), $\}$;

c. Script yang digunakan untuk membuat window fullscreen fscommand("fullsccreen","true");

d. Script yang digunakan untuk membuat sound

on (release) \{

stopAllSounds();

loadMovieNum("_IRMAN.swf",1);

4) Merekam dan mengedit suara

Pada aplikasi multimedia pembelajaran berbasis game ini, nanti akan ada suara penulis sebagai narator yang akan membacakan materi dan kuis pada materi pengenalan abjad. Untuk mendapatkan suara tersebut, penulis malakukan perekaman suara menggunakan miccrophone yang dibantu dengan Sofware CoolEdit Pro 2.0 yang bisa merekan data berupa gelombang audio, dan kemudian di edit kembali dengan menggunakan sofware yang sama, lebih jelasnya daat dilihat pada Gambar 7 .

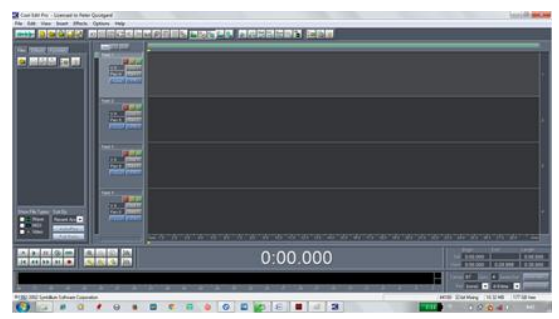

Gambar. 7 Tampilan sofware cooledit pro 2.0

5) Test movie dan Publikasi File

Setelah semua tahap aplikasi meultimedia ini selesai, tahap selanjutnya adalah melakukan test movie dengan tujuan untuk megetahui apakah aplikasi dapat berjalan dengan baik atau tidak (terjadi error). Apabila masih terdapat kesalahan atau error maka harus dilakukan perbaikan hingga aplikasi berjalan dengan baik. Test movie ini akan menghasilkan file dengan ekstensi .swf. Tahap selanjutnya yaitu mempublikasi file utama menjadi .exe dengan tujuan agar aplikasi dapat berjalan pada komputer tanpa harus menginstal flash.

6) Tampilan Hasil

a. Halaman intro

UNITEX Vol 11 No.2 Juli - Desember 2018 | p-ISSN 2089-3957 | e-ISSN 2580-2585 
Pada halaman intro, terdapat animasi judul dari media pembalajaran serta loading dan tombol start. jika tombol start di klik maka akan muncul menu dari intro.

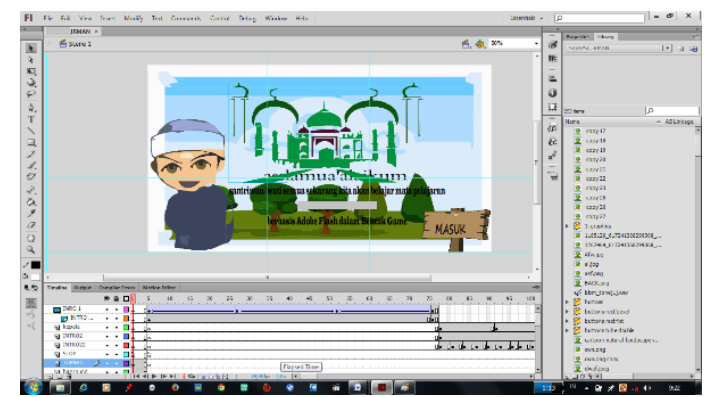

Gambar 7. Halaman intro

b. Halaman menu utama

Pada halaman menu utama terdapat 4 tombol yaitu profil guru, $\mathrm{SK} / \mathrm{KD}$, materi, dan game.

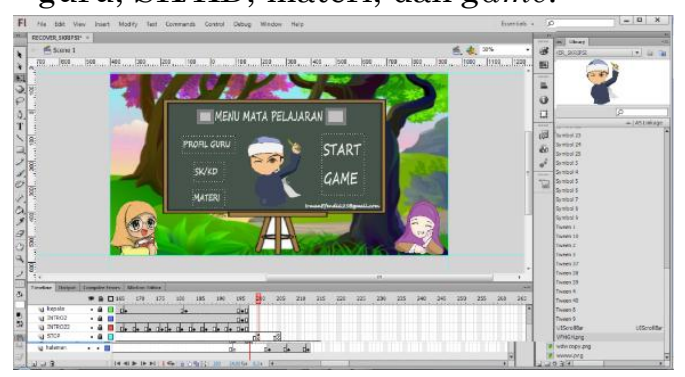

Gambar 8. Halaman Menu Utama

\section{Tahap Implementasi (Implementation)}

Tahap implementasi yaitu pengujian aplikasi dengan menggunakan metode blackbox adalah pengujian yang dilakukan antar muka perangkat lunak, pengujian ini dilakukan untuk memperlihatkan bahwa fungsi-fungsi bekerja dengan baik dalam artian masukan diterima dengna benar dan keluaran yang dihasilkan benar-benar tepat, penginterasian eksternal data dapat berjalan dengan baik. Berikut adalah tabel identifikasi dan rencana pengujian. 
Tabel 2 Identifikasi dan rencana pengujian

\begin{tabular}{|c|c|c|c|c|}
\hline No & Kelas uji & Butir uji & $\begin{array}{c}\text { Tingkat } \\
\text { pengujian }\end{array}$ & $\begin{array}{c}\text { Jenis } \\
\text { pengujian }\end{array}$ \\
\hline 1 & 2 & 3 & 4 & 5 \\
\hline 1 & $\begin{array}{l}\text { Pengujian } \\
\text { menu intro }\end{array}$ & Masuk menu intro & Pengujian unit & Blackbox \\
\hline 2 & $\begin{array}{l}\text { Pengujian } \\
\text { menu utama }\end{array}$ & $\begin{array}{l}\text { Menu intro } \\
\text { Menu materi } \\
\text { Menu game } \\
\text { Menu profil }\end{array}$ & Pengujian unit & blackbox \\
\hline 3 & $\begin{array}{l}\text { Pengujian } \\
\text { menu game }\end{array}$ & Masuk menu game & Pengujian unit & blackbox \\
\hline 4 & $\begin{array}{l}\text { Pengujian } \\
\text { materi }\end{array}$ & $\begin{array}{l}\text { Masuk menu } \\
\text { MAteri }\end{array}$ & Pengujian unit & blackbox \\
\hline 5 & $\begin{array}{l}\text { Pengujian } \\
\text { menu profil }\end{array}$ & Masuk menu profil & Pengujian unit & blackbox \\
\hline
\end{tabular}

D. Tahap Evaluasi (Evaluation)

Dalam proses ini aplikasi yang sudah jadi diburning ke cd dengan menggunakan perangkat nerostart essential dan dikemas sehingga produk menjadi siap pakai. Dalam aplikasi ini terdapat bebrapa file pendukung yaitu

1. File.exe, yaitu file yang menjalankan progra atau program player

2. File.swf, yaitu flash movie sebagai kelengkapan

3. File.apk yaitu file yang menjalankan program ke android

\section{Simpulan}

Media pembelajaran game berbasis android untuk pengenalan abjad dalam bentuk game adalah sebuah perancangan pembelajaran yang dibuat agar memenuhi kebutuhan peserta didik serta dapat meningkatkan efektifitas pembelajaran, di mana kebutuhan tersebut mencakup beberapa hal dalam proses pembelajaran(CAI) adalah tipe CBI yang dapat digunakan sendiri atau digunakan bersama dengan sistem instruksional lain. Perangkat lunak yang digunakan berfungsi untuk membantu proses pembelajaran. Manfaat media berupa smartphone meliputi penyajian informasi, isi materi pelajaran dan latihan atau kombinasinya.

UNITEX Vol 11 No.2 Juli - Desember 2018 | p-ISSN 2089-3957 | e-ISSN 2580-2585 


\section{Daftar Pustaka}

Falahudin, Iwan. 2014. Pemanfaatan Media dalam Pembelajaran. Jurnal Lingkar Widyaiswara. Edisi 1 No. 4, Oktober - Desember 2014, ISSN: 2355-4118, p.104-117

Haryawan, Agus. 2014. Pengembangan Media Pembelajaran Berbasis Adobe Flash CS6 untuk Meningkatkan Motivasi dan Prestasi Belajar Mata Kuliah

Pemrograman Bahasa Rakitan di Politama Surakarta. Jurnal POLITEKNOSA INS Vol. XIII No. 1, Maret 2014, p.61-72

Irsa, Dora, dkk. 2015. Perancangan Aplikasi Game Edukasi Pembelajaran Anak Usia Dini Menggunakan Linear Congruent Method (LCM) Berbasis Android. Jurnal Informatika Global. Volume 6 No. 1 Desember 2015, E-ISSN : 2477-3786, p.7-14

Juansyah, Andi. 2015. Pembangunan Aplikasi Child Tracker Berbasis AssistedGlobal Positioning System (A-GPS) dengan Platform Android. Jurnal Ilmiah Komputer dan Informatika (KOMPUTA). Edisi 1 Volume 1, Agustus 2015, ISSN : 2089-9033, p.1-7

Pebriani. 2012. Peningkatan Kemampuan Anak Mengenal Huruf Melalui Permainan Menguraikan Kata di Taman Kanak-Kanak Negeri Pembina Agam. Jurnal Pesona PAUD, Vol. 1 No. 1, September 2012, p.1-11

Putra, Dian Wahyu, dkk. 2016. Game Edukasi Berbasis Android Sebagai Media Pembelajaran untuk Anak Usia Dini. Jurnal Informatika Merdeka Pasuruan (JIMP). Vol.1, No. 1 Maret 2016, ISSN.2502-5716, p.46-58 